\title{
Anthós
}

\section{Lessons from the COVID-19 Pandemic on the Role of Socioeconomic Status in Health Outcomes}

Leila Karout

Portland State University

Follow this and additional works at: https://pdxscholar.library.pdx.edu/anthos

Part of the Medicine and Health Sciences Commons, and the Social and Behavioral Sciences Commons

Let us know how access to this document benefits you.

\section{Recommended Citation}

Karout, Leila (2021) "Lessons from the COVID-19 Pandemic on the Role of Socioeconomic Status in Health Outcomes," Anthós: Vol. 10: Iss. 1, Article 16.

https://doi.org/10.15760/anthos.2021.10.1.16

This open access Article is distributed under the terms of the Creative Commons Attribution-NonCommercialShareAlike 4.0 International License (CC BY-NC-SA 4.0). All documents in PDXScholar should meet accessibility standards. If we can make this document more accessible to you, contact our team. 


\title{
Lessons from the COVID-19 Pandemic on the Role of Socioeconomic Status in Health Outcomes
}

\author{
Leila Karout
}

\section{Current Characteristics and Outcomes of COVID-19}

The SARS-CoV-2 (COVID-19) pandemic has evoked extreme circumstances for many around the world. As of the time of this writing, the World Health Organization has reported 159,319,384 confirmed cases of COVID-19 and 3,311,780 deaths globally. The United States alone has seen a total of 32,424,637 confirmed cases and 576,814 total deaths. ${ }^{1}$ While risk factors, clinical characteristics of patients, mortality, and morbidity are all under consistent study, the information we have now on the pandemic and its effects on various populations shows similar patterns and themes. Current research has shown that severe obesity, hypertension, diabetes, cardiovascular diseases (CVDs), and kidney disease are the most prevalent underlying health conditions for individuals with COVID-19. These conditions have demonstrated an increase in morbidity of the virus. ${ }^{2,3,4,5,6,7.8,9}$ As of May 18th, 2020, the CDC reported $8,134(76.4 \%)$ of deaths from COVID 19 to be associated with at least one underlying medical condition (including $83.1 \%$ of deaths for those under 65 years). The most common being cardiovascular disease $(60.9 \%)$, diabetes mellitus (39.5\%), chronic kidney disease (20.8\%), and chronic lung disease $(19.2 \%)^{7}$

SES is a complex composition of social and economic factors that influence an individual, or a community's experiences. Socioeconomic status (SES) plays a substantial role in an individual's life due to the resources and opportunities that come along with it such as education, quality healthcare access, financial stability, social status, and race/ethnicity as a socioeconomic factor. ${ }^{38}$ Individuals from lower SES are at a higher risk for illness susceptibility and severity. ${ }^{12,13}$ This is especially prevalent during the current pandemic, where daily life has drastically changed, including detrimental social and financial challenges for many. Psychological stress due to restrictions on social behavior, the ability to see loved ones, and having an unstable occupation, has created outcomes such as depression, health anxiety, and financial worry. ${ }^{18}$ Low SES can aggravate these outcomes due to the higher likelihood of risk factors such as pre-existing financial instability, lack of healthcare access, and the higher prevalence of pre-existing diseases associated with COVID-19 such as asthma, CVD, hypertension, chronic kidney disease (CKD), diabetes, and obesity. ${ }^{10,9,19,20}$ Therefore, it is essential to examine the role of SES during the COVID-19 pandemic to be better prepared to protect the most at-risk populations and find room for improvement in the

\footnotetext{
${ }^{1}$ See endnotes for references.
} 
healthcare system that would support optimal prevention and treatment of such a virus universally.

\section{The Complex Role of SES as a Risk Factor for COVID-19 Severity and Susceptibility}

Current trends are highlighting the association between COVID-19 rates and SES, as well as race/ethnicity. New York City is an important example, as it experienced the highest rates of infections in the United States. ${ }^{10}$ The Bronx, a borough of New York City, has disproportionate rates of hospitalization and death than any other region within the city. It also ranks last in New York State for health outcomes, quality of life, and socioeconomic factors, ${ }^{9}$ while consistently showing the highest rates of hypertension, diabetes, and asthma, exacerbated by their socioeconomic conditions. ${ }^{10}$ Furthermore, Palaiodimos et al., found obesity to be the most significant factor in COVID-19 mortality and severity, even after adjusting for other clinical characteristics such as diabetes, coronary artery disease, heart failure, COPD, CKD, and smoking. Comparingly, about $33 \%$ of residents in the Bronx are obese, more than any other borough in New York City. Diabetes and hypertension are also most prevalent in the Bronx compared to other New York counties. ${ }^{9}$ These associations are not exclusive to New York City. According to the CDC, the age-adjusted hospitalization rates for African-American, Alaska Native, and American Indian populations are 5 times that of White people. Hospitalization rates for Hispanic/Latino ethnicity are 4 times that of Non-Hispanic White people. ${ }^{39}$ Black, Asian, and Minority Ethnic (BAME) populations are at increased risk for poor health outcomes due to socioeconomic inequalities such as less access to healthcare, and higher rates of disease such as diabetes, hypertension, obesity, and cardiovascular conditions. ${ }^{35,36}$

The association between COVID-19 infection and SES is becoming more clear and is consistent with previous pandemics such as the 2009/2010 H1N1 outbreak. ${ }^{9,11}$ These inequalities can be contributed to differences in living conditions, occupation, and systemic challenges. ${ }^{9}$ Pre-existing inequalities have been reinforced by the COVID-19 pandemic. For example, the CDC reported that $33 \%$ of COVID infections were represented by Black Americans in a study of 99 counties, despite making up $18 \%$ of the population. Black counties also experience six times the death rate compared to the majority of White counties. ${ }^{25}$ Similarly in Chicago, African American residents represented 72 percent of COVID-19 deaths, while making up only 29 percent of Chicago's population in April of $2020 .^{28}$ Golestaneh et al., also found Black Americans to be more likely to test positive and be hospitalized due to COVID-19 even when clinical and sociodemographic factors were adjusted. ${ }^{25}$ Such differences can be related to several factors, such as minority populations having higher rates of comorbidities, lower SES (thus lower chance of access to care), and the fact that 
the majority of front-line workers are of minority and low SES backgrounds. ${ }^{27}$ Financial distress and poor health care access are linked to adverse health outcomes and heavier disease burden over the course of life. This is significant as we know that older populations are at particularly higher risk for COVID-19 and experience worse morbidity and mortality. ${ }^{26}$ Income inequality within society has damaging effects on the physical and social well-being of populations. ${ }^{13}$ In a longitudinal analysis by Robinette et al., the chance of developing and/or having more than two chronic health conditions decreased for every 10,000 dollar increment in neighborhood income. ${ }^{12}$

The Distressed Communities Index (DCI) can be a useful tool to quantitatively examine the relationships between SES and health outcomes such as with COVID-19. The DCI accounts for seven socioeconomic factors such as unemployment, education, poverty rate, median income, business growth, and housing vacancies. A higher county DCI score was associated with more COVID-19 deaths per 100,000 people than non-distressed counties. While this can be explained by the higher prevalence of comorbidities and age, the association between COVID-19 mortality and socioeconomic status was stronger than that with underlying medical conditions. ${ }^{29}$

Pre-existing medical conditions are well known to put an individual at a much higher risk for poor COVID-19 outcomes. However, pre-existing medical conditions on their own do not represent the most accurate estimation for infection severity and susceptibility. Exposure to the virus and access to optimal treatment and preventative care is very significant when examining vulnerability to COVID-19 and predicting the severity of prognosis. The work of Wiemer et al. uses a predictive model to examine the vulnerability to "in-patient hospitalization for respiratory conditions for the U.S. and how vulnerability varies by education, income, and race-ethnicity" using an index of relative vulnerability (VI). ${ }^{2}$

Substantial differences in vulnerability are found due to inequalities across race and socioeconomic status particularly in terms of pre-existing health conditions. Notably, these disparities are present earlier in life, before age 65. Non-Hispanic (NH) Blacks were found to have more risk factors on average than Non-Hispanic Whites, including a higher prevalence of hypertension but had lower VI among all ages. Vulnerability was found to be $60 \%$ higher for those with an education of high school or less than with a college degree, and VI was higher for those in the lower quartile of household income across all age groups. Among those who are 25 years or older, a 3 -fold difference was found between individuals in the lowest quartile of household income than those in the top quartile. Wiemer makes the important distinction between exposure and susceptibility to infection. While no difference was found in vulnerability index (VI) between $\mathrm{NH}$ Blacks and $\mathrm{NH}$ Whites, when examined within age groups (specifically 45-64, 65+) NH Blacks had higher VI. This points to significant differences in exposure that can be 
related to varying health conditions among the two populations. Likewise, Hispanics were found to have lower VI than NH Whites and NH Blacks despite high hospitalization rates, suggesting significant exposure rates. ${ }^{2}$

\section{Linking SES and Poor Health Outcomes from a Biological Perspective}

Low socioeconomic status can be a source of psychological stress for individuals and families due to financial and social burdens. When the stressors associated with low SES are experienced early in life, and/or consistently throughout life, overall health is at risk. Thus, during a pandemic of a highly contagious virus such as COVID-19, SES becomes a risk factor for increased severity of infection. A growing body of evidence is continuing to reveal the biological link between low SES and adverse effects such as cellular senescence. ${ }^{14,15,17}$ Cellular senescence refers to the cessation of cell division. Chronic cellular senescence can occur in response to long-term stress and negatively impacts the immune system. ${ }^{17,42}$ A study by Elwenspoek et al., found that in a group of healthy participants, early life adversity (ELA), promoted cytomegalovirus (CMV), an important driving force of immunosenescence--the progressive decline of the immune system. ${ }^{17}$ Low SES was also shown by Dowd \& Aiello to be associated with an impaired immune response to CMV. This further suggests that low SES is a risk factor for worse health outcomes and poorer immune response to infection. ${ }^{37}$

The relationship between immune dysfunction, ELA, and SES is critical towards understanding the role SES has on the severity and susceptibility of COVID-19. Data has shown that a dysfunctional immune cell response and abundance of senescent cells, will negatively impact the prognosis of COVID-19. Senescent immune cells produce pro-inflammatory cells ${ }^{16}$ and show elevated levels of cytotoxicity. ${ }^{17}$ Accelerated and chronic immunosenescence of cells would lead to a higher likelihood of mortality and morbidity of disease. ${ }^{21}$ Severe COVID-19 patients have more non-functional, and senescent immune cells, as well as increased cytokine release storm which is an inflammatory response by immune cells to endogenous/exogenous stress. Thus, COVID-19 can mimic immunosenescence, as outlined by Omarjee et al. ${ }^{24}$ Proper immune function is necessary for the least severe COVID-19 outcome. ${ }^{16}$ The association between an altered immune response to infection and SES highlights one way in which low SES individuals are especially vulnerable to COVID-19 severity and susceptibility. It is important to address the challenges associated with low SES, to ensure proper prevention and treatment of COVID-19 and other infectious diseases. Prevention strategies can include mental health screenings, counseling services, and access to primary care for low SES communities.

Improving Access to Care and Rethinking the Healthcare System for Health 


\section{Equity}

It has become clear that significant discrepancies exist within different populations of society. Data has pointed to disproportionate COVID-19 infection rates, illness severity, susceptibility, and morbidity. To address these issues, access to care must be held as a priority. Challenges within the healthcare system should be improved and acknowledged. Even before the COVID-19 pandemic, socioeconomic inequalities have been a barrier to receiving healthcare, especially primary care facilities that include not only treatment but preventative services. The U.S. has struggled to provide affordable access to care even before the pandemic, and now these issues are becoming more prevalent. In 2018, approximately $8.5 \%$ of the population ( 27.5 million people) were uninsured. This is important as the majority of the population receives insurance through their employer, employer-sponsored insurance (ESI). During an economic crisis exasperated by a pandemic, job loss is high and thus health insurance is low when it is needed most. As of April of 2020, the unemployment rate hit 14.7\%, the lowest since World War II. ${ }^{30}$ And, if employment is not lost, health insurance coverage could still be at risk due to employers cutting costs. On the other hand, a public insurance system could unlink employment and insurance, improving some of the downfalls of private insurance. ${ }^{31}$ The quality of health coverage is influenced by the premium paid per month, meaning quality care decreases with lower income. This can also influence whether an individual seeks care due to extra costs from copays, even with ESI. ${ }^{34}$ Likewise, in a poll regarding seeking care during COVID-19, 68\% of Americans state they would delay or avoid seeking care if they suspected having symptoms of the virus due to cost. ${ }^{33}$ Similar reluctances to seek care was observed in another survey further emphasizing the association between SES and unwillingness to seek care for financial reasons during COVID-19. ${ }^{41}$ Measures such as the Families First Coronavirus Response Act requires insurers such as Medicare, Medicare Advantage, and Medicaid to eliminate copayments, deductibles and coinsurance payments for COVID-19 testing services. However, this does not take into account services for treatment and hospitalization. The same is seen with the Coronavirus Aide, Relief and Economic Security Act (CARES), where costs associated with treatment are not addressed. ${ }^{33}$ Blumenthal et al. highlights the flaws within ESI including the lack of implementation of laws such as the Affordable Care Act (ACA) due to lack of education about eligibilities, and that 14 states have opted out of the ACA. ${ }^{31}$

Smith and Fraser $^{32}$ outline important strategies for improving systemic challenges such as improving and expanding data and analytic capabilities, expanding public health laboratory capacities, and increasing the number of CDC public health advisors who work with staff in ministries of health and governmental public health. Furthermore, it is notable that "the budget for the CDC's Public Health Emergency Preparedness cooperative agreement has been 
reduced by almost one third" from federal fiscal year (FFY) 2002 to FFY2019 despite congress having invested in federal, state, and local public health preparedness programs after events of September 11 and the anthrax attack. ${ }^{32}$ Quality data and analytics are also necessary for adequate disease surveillance and to make timely, informed decisions. This is significant for reducing inequalities within SES by providing data on different communities and ultimately using this to develop prevention and response strategies that will therefore address the most vulnerable populations, and thus decrease infection overall. Addressing SES challenges is also essential for disease surveillance as universal access to care would ensure significantly more individuals being tested ${ }^{23}$ Such strategies can drastically improve the preparedness capabilities of the public health system. The U.S. had $17.7 \%$ of the nation's gross domestic product (GDP) spent on healthcare in 2018, compared to the Organization for Economic Cooperation and Development (OECD) average of 8.8\%, with disease burden being $28 \%$ compared to the OECD average of $17.5 \%$. These diseases include those that put Americans at higher risk of COVID-19: hypertension, heart disease, diabetes, chronic lung disease. ${ }^{34}$

\section{Lessons from the Pandemic}

While the U.S. population constitutes $6 \%$ of the world's population, the U.S. represents $26 \%$ of COVID-19 cases and $24 \%$ of COVID-19 deaths. ${ }^{31}$ This alone is cause for more focus on research and implementation of strategies to address issues within the healthcare system. The relationship between SES and the health outcomes during the COVID-19 pandemic serves as a lesson to be learned from. The inequalities we see among different SES populations and raceethnicity can be attributed to a substantial wealth gap, systemic inequalities, and a flawed healthcare system. Specifically, the COVID-19 pandemic has also emphasized the crucial need for affordable healthcare that is accessible to all, regardless of SES. This is necessary for the health of the country, as well as crucial to properly address public health emergencies such as COVID-19. It is also important to note that the outcomes of the current pandemic have been experienced before, such as during the $2009 \mathrm{H} 1 \mathrm{~N} 1$ influenza pandemic, where vulnerable populations experienced the worst outcomes due to poor healthcare access and increase susceptibility and exposure to the virus. ${ }^{40}$ By acknowledging the populations most at risk, the cause of said risk, and addressing preparedness capacities and strategies outlined above by Smith and Fraser, ${ }^{32}$ we may be much better prepared to optimally control public health emergencies. Furthermore, it is important to implement strategies for increasing data collection of race and ethnicity such as the Equitable Data Collection and Disclosure on COVID-19 Act, which aims to establish a standardized repository for race/ethnicity data related to COVID-19. ${ }^{28}$ Research on the relationship between SES and increased prevalence 
on disease burden is also important as the link has been extensively studied, but the root cause of this association is not as well known. A public health approach that recognizes the social, environmental, economic, and personal impact of health at the individual and community level is necessary to begin to solve such health disparities.

\section{References}

1. World Health Organization (WHO). 2020. United States of America: WHO Coronavirus Disease (COVID-19) Dashboard. https://covid19.who.int/region/amro/country/us

2. Wiemers, E. E., Abrahams, S., AlFakhri, M., Hotz, V. J., Schoeni, R. F., \& Seltzer, J. A. (2020). Disparities in Vulnerability to Severe Complications from COVID-19 in the United States. National Bureau of Economic Research. https://doi.org/10.3386/w27294

3. Alcendor, D. J. (2020). Racial Disparities-Associated COVID-19 Mortality among Minority Populations in the US. Journal of Clinical Medicine, 9(8), 2442. doi: $10.3390 /$ jcm 9082442

4. Adhikari, S., Meng, S., Wu, YJ. et al. (2020). Epidemiology, causes, clinical manifestation and diagnosis, prevention and control of coronavirus disease (COVID-19) during the early outbreak period: a scoping review. Infect Dis Poverty 9, https://doi.org/10.1186/s40249-020-00646-X

5. A. Clark, M. Jit, C. Warren-Gash, B. Guthrie, H.H.X. Wang, S.W. Mercer, et al. (2020) Global, regional, and national estimates of the population at increased risk of severe COVID-19 due to underlying health conditions in 2020: a modelling study. The Lancet Global Health. https://doi.org/10.1016/S2214$\underline{109 X(20) 30264-3}$

6. Shi, Y., Yu, X., Zhao, H. et al. (2020). Host susceptibility to severe COVID 19 and establishment of a host risk score: findings of 487 cases outside Wuhan. Crit Care 24, 108. https://doi.org/10.1186/s13054-020-2833-7

7. Wortham JM, Lee JT, Althomsons S, et al. (2020). Characteristics of Persons Who Died with COVID-19 - United States. MMWR Morb Mortal Wkly Rep 2020;69:923-929. http://dx.doi.org/10.15585/mmwr.mm6928e1

8. Chen T, Wu D, Chen H, Yan W, Yang D, Chen G, Ma K, Xu D, Yu H, Wang H, Wang T, Guo W, Chen J, Ding C, Zhang X, Huang J, Han M, Li S, Luo X, 
Zhao J, Ning Q. (2020). Clinical characteristics of 113 deceased patients with coronavirus disease 2019: retrospective study. BMJ. 368:m1091.

10.1136/bmj.m1091.

9. Palaiodimos, L., Kokkinidis, D. G., Li, W., Karamanis, D., Ognibene, J., Arora, S., Southern, W. N., \& Mantzoros, C. S. (2020). Severe obesity, increasing age and male sex are independently associated with worse in-hospital outcomes, and higher in-hospital mortality, in a cohort of patients with COVID-19 in the Bronx, New York. Metabolism: clinical and experimental, 108, 154262. https://doi.org/10.1016/j.metabol.2020.154262

10. Juan Vazquez, Tanzina Islam, Jonathan Gursky, Jennifer Beller, and Daniel Jose Correa. (2020). Access to Care Matters: Remote Health Care Needs During COVID-19. Mary Anne Liebert Publishers. http://doi.org/10.1089/tmj.2020.0371

11. Clark E, Fredricks K, Woc-Colburn L, Bottazzi ME, Weatherhead J. (2020). Disproportionate impact of the COVID-19 pandemic on immigrant communities in the United States. PLoS Negl Trop Dis, 14(7): e0008484. https://doi.org/10.1371/journal.pntd.0008484

12. Robinette, J.W., Charles, S.T. \& Gruenewald, T.L. (2017). Neighborhood Socioeconomic Status and Health: A Longitudinal Analysis. J Community Health 42, 865-871. https://doi.org/10.1007/s10900-017-0327-6

13. Kate E. Pickett, Richard G. Wilkinson, Income inequality and health: A causal review. (2015). Social Science \& Medicine, Volume 128 Pages 316-326. https://doi.org/10.1016/j.socscimed.2014.12.031.

14. Ockenburg, S \& Bos, E \& Jonge, Peter \& van der Harst, Pim \& Gans, Reinold \& Rosmalen, Judith. (2015). Stressful life events and leukocyte telomere attrition in adulthood: A prospective population-based cohort study. Psychological medicine. -1. 1-10. 10.1017/S0033291715000914.

15. Dowd, J. B., \& Aiello, A. E. (2009). Socioeconomic differentials in immune response. Epidemiology (Cambridge, Mass.), 20(6), 902-908.

https://doi.org/10.1097/EDE.0b013e3181bb5302

16. Holuka, C., Merz, M. P., Fernandes, S. B., Charalambous, E. G., Seal, S. V., Grova, N., \& Turner, J. D. (2020). The COVID-19 Pandemic: Does Our Early Life Environment, Life Trajectory and Socioeconomic Status Determine Disease Susceptibility and Severity? International Journal of Molecular Sciences, 21(14), 
5094. doi:10.3390/ijms21145094

17. Elwenspoek Martha M. C., Sias Krystel, Hengesch Xenia, Schaan Violetta K., Leenen Fleur A. D., Adams Philipp, Mériaux Sophie B., Schmitz Stephanie, Bonnemberger Fanny, Ewen Anouk, Schächinger Hartmut, Vögele Claus, Muller Claude P., Turner Jonathan D. (2017). T Cell Immunosenescence after Early Life Adversity: Association with Cytomegalovirus Infection. Frontiers in Immunology. 8. 1263. DOI 10.3389/fimmu.2017.01263. 1664-3224

18. Matthew T. Tull, Keith A. Edmonds, Kayla M. Scamaldo, Julia R. Richmond, Jason P. Rose, Kim L. Gratz. (2020). Psychological Outcomes Associated with Stay-at-Home Orders and the Perceived Impact of COVID-19 on Daily Life. Psychiatry Research, Volume 289, 2020, 113098, ISSN 0165-1781. https://doi.org/10.1016/j.psychres.2020.113098.

19. Singu, S., Acharya, A., Challagundla, K., \& Byrareddy, S. N. (2020). Impact of Social Determinants of Health on the Emerging COVID-19 Pandemic in the United States. Frontiers in public health, 8, 406. https://doi.org/10.3389/fpubh.2020.00406

20. Hatef, E., Chang, H. Y., Kitchen, C., Weiner, J. P., \& Kharrazi, H. (2020). Assessing the Impact of Neighborhood Socioeconomic Characteristics on COVID-19 Prevalence Across Seven States in the United States. Frontiers in public health, 8, 571808. https://doi.org/10.3389/fpubh.2020.571808

21. Childs, B., Durik, M., Baker, D. et al. (2015). Cellular senescence in aging and age-related disease: from mechanisms to therapy. Nat Med 21, 1424-1435. https://doi.org/10.1038/nm.4000

22. Matthew T. Tull, Keith A. Edmonds, Kayla M. Scamaldo, Julia R. Richmond, Jason P. Rose, Kim L. Gratz. (2020). Psychological Outcomes Associated with Stay-at-Home Orders and the Perceived Impact of COVID-19 on Daily Life. Psychiatry Research, Volume 289, 113098. https://doi.org/10.1016/j.psychres.2020.113098.

23. Hatef, E., Chang, H. Y., Kitchen, C., Weiner, J. P., \& Kharrazi, H. (2020). Assessing the Impact of Neighborhood Socioeconomic Characteristics on COVID-19 Prevalence Across Seven States in the United States. Frontiers in public health, 8, 571808. https://doi.org/10.3389/fpubh.2020.571808

24. Omarjee, L., Janin, A., Perrot, F., Laviolle, B., Meilhac, O., \& Mahe, G. (2020). Targeting T-cell senescence and cytokine storm with rapamycin to 
prevent severe progression in COVID-19. Clinical immunology (Orlando, Fla.), 216, 108464. https://doi.org/10.1016/j.clim.2020.108464

25. Ladan Golestaneh, Joel Neugarten, Molly Fisher, Henny H. Billett, Morayma Reyes Gil, Tanya Johns, Milagros Yunes, Michele H. Mokrzycki, Maria Coco, Keith C. Norris, Hector R. Perez, Shani Scott, Ryung S. Kim, Eran Bellin. (2020). The association of race and COVID-19 mortality. EClinicalMedicine, Volume 25, 2020, 100455. https://doi.org/10.1016/j.eclinm.2020.100455.

26. McMaughan, D. J., Oloruntoba, O., \&amp; Smith, M. L. (2020).

Socioeconomic Status and Access to Healthcare: Interrelated Drivers for Healthy Aging. Frontiers in Public Health.

https://doi.org/https://doi.org/10.3389/fpubh.2020.00231

27. Dorn, A. V., Cooney, R. E., \& Sabin, M. L. (2020). COVID-19 exacerbating inequalities in the US. Lancet (London, England), 395(10232), 1243-1244. https://doi.org/10.1016/S0140-6736(20)30893-X

28. Martin-Howard, S. and Farmbry, K. (2020). Framing a Needed Discourse on Health Disparities and Social Inequities: Drawing Lessons from a Pandemic. Public Admin Rev, 80: 839-844. https://doi.org/10.1111/puar.13265

29. Hawkins, R. B., Charles, E. J., \&amp; Mehaffrey, J. H. (2020). Socio economic status and COVID-19-related cases and fatalities. ScienceDirect, Public Health, 189, 129-134.

https://doi.org/https://doi.org/10.1016/j.puhe.2020.09.016

30. Cole, B. (2020). The impact of the COVID-19 pandemic on access to healthcare, Health Policy Brief No. 17. National Academy of Social Insurance. https://www.nasi.org/research/2020/impact-covid-19-pandemic-access-health $\underline{\text { care }}$

31. Blumenthal, D., Fowler, E. J., Abrams, M., \& Collins, S. R. (2020). Covid-19 - Implications for the Health Care System. The New England Journal of Medicine. https://doi.org/10.1056/NEJMsb2021088

32. Nathaniel Smith, Michael Fraser. (2020). Straining the System: Novel Coronavirus (COVID-19) and Preparedness for Concomitant Disasters. American Journal of Public Health 110, no. 5, pp. 648-649. https://doi.org/10.2105/AJPH.2020.305618

33. King, J. S. (2020). Covid-19 and the Need for Health Care Reform. New 
England Journal of Medicine. https://doi.org/10.1056/NEJMp2000821

34. Rollston, R., \& Galea, S. (2020). COVID-19 and the Social Determinants of Health. American Journal of Health Promotion, 34(6), 687-689.

https://doi.org/10.1177/089nlm0117120930536b

35. Rose, T. C., Mason, K., Pennington, A., McHale, P., Taylor-Robinson, D. C., \& Barr, B. (2002). Inequalities in COVID19 mortality related to ethnicity and socioeconomic deprivation. MedRxiv. https://doi.org/ https://doi.org/10.1101/2020.04.25.20079491

36. Kopel Jonathan, Perisetti Abhilash, Roghani Ali, Aziz Muhammad, Gajendran Mahesh, Goyal Hemant. (2020). Racial and Gender-Based Differences in COVID-19. Frontiers in Public Health.

418. https://doi.org/10.3389/fpubh.2020.00418

37. Dowd, J. B., \& Aiello, A. E. (2009). Socioeconomic differentials in immune response. Epidemiology (Cambridge, Mass.), 20(6), 902-908.

https://doi.org/10.1097/EDE.0b013e3181bb5302

38. Martha J. Farah. (2017). The Neuroscience of Socioeconomic Status:

Correlates, Causes, and Consequences. ScienceDirect, Neuron. Volume 96, Issue 1, Pages 56-71.

https://doi.org/10.1016/j.neuron.2017.08.034.(http://www.sciencedirect.com/scien ce/article/pii/S0896627317307493)

39. Julius M Wilder. (2020). The Disproportionate Impact of COVID-19 on Racial and Ethnic Minorities in the United States. Clinical Infectious Diseases, ciaa959. https://doi.org/10.1093/cid/ciaa959

40. Bibbins-Domingo, K. (2020). This Time Must Be Different: Disparities During the COVID-19 Pandemic. Annals of Internal Medicine. https://doi.org/https://doi.org/10.7326/M20-2247

41. Witters, D. (2021). In U.S., 14\% With Likely COVID-19 to Avoid Care Due to Cost. Gallup.com. https://news.gallup.com/poll/309224/avoid-care-likely-covid due-cost.aspx.

42. Regulski, M. J. (2017). Cellular Senescence: What, Why, and How. Wounds. https://www.woundsresearch.com/article/cellular-senescence-what-why-and-how 